\title{
Science fiction and fantasy
}

\section{A guide to resources on the Web}

\author{
by Wendi Arant and Hal W. Hall
}

G iven the popular nature of science fiction and fantasy (SFF), there are millions of sites on the Internet dedicated to specific creators, genres, movements, history, scholarship, and fandom surrounding fiction, films, games, and television. The plethora of Web pages is problematic for the user, which makes having a guide useful.

Science fiction has evolved from its genre or pulp beginnings to an overlapping mixture of books, magazines, motion pictures, television, comics, conventions, and gaming. Each subset has its own communication infrastructure on the Web and in the world. This listing focuses primarily on the print subset of science fiction, with a nod to movies, television, and other media. In addition, science fiction and fantasy can arguably include such subgenre as horror, supernatural, and weird fiction, which we have tried to characterize through inclusion of some sites in these areas.

Selection of sites in this listing was based on usefulness (as in omnibus sites) and on authority (the accuracy of the material and the expertise of the source). An effort has been made to include sources that are available without a subscription and with unrestricted access.

\section{Getting started}

The sites listed here are arguably the most com prehensive and most authoritative available on the Web. Locus magazine and SF Site are both content rich with useful information and have indispensable links to other useful sites that have been evaluated and kept up-to-date.

- Locus Online. This is perhaps the best first place to check when looking for science fiction and fantasy information on the Web. While focusing on textual incarnations of SFF, it does cover other media sporadically, such as cinema, television, gaming, and comics. This valuable re-

\section{LOCUS sorline source is inity} up-to-date (keeping in sync with the monthly publication of the print version), and includes review sites, publishing and entertainment news, and convention information, as well as access to a good compilation of contemporary author Web sites with the Locus Online: Authors, Artists, Editors Page. Locus also includes fairly comprehensive access to scholarly resources with the Locus Index to Science Fiction, which includes a number of valuable reference sources such as Brown and Contento's Locus Index to Sclence

\section{About the authors}

Wendi Arant is humanities bibliographerat the Texas A\&M University Libraries, e-mail: warant@tamu.edu; Hal W. Hall is a recognized science fiction scholar and bibliographer, author of several genre fiction studies, and curator of science fiction at the Cushing Library at Texas A \& MUniversity, e-mail: hal-hall@tamu.edu 
Fiction (1984 to 2002); the Index to Science Fiction Antbologies and Collections, Science Fiction, Fantasy, \& Weird Fiction Magazine Checklist, Mys tery Sbort Fiction: 1990-2000, and the listing of Locus Awards. Access: http://www locusmag.com.

- SF Site: The Best in Science Fiction and Fantasy. Updated on a monthly basis, this site is a good source of current information and news on books and other SFF media, featuring reviews and interviews of contemporary authors, readings lists and links to fan sites, newsgroups, and zines. The "Science Fact" section provides links to institutions and government research sites concemed with technology and science discoveries, which would be of interest to fans and scholars and no doubt of great practical use to creators of science fiction. Particularly noteworthy are the authors page for links to author-specific Web sites and the Internet Speculative Fiction DataBase (ISFDB), which provides bibliographic control of more than 100,000 titles (with an admitted emphasis on text creations) searchable by name, title, year, or series. The ISFDB is a good starting point to get an overview of an author's work, but should be supplemented by other sources. Access: http://www.sfsite.com/.

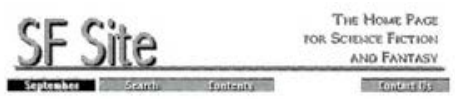

\section{Reference sources and megasites}

- Science Fiction and Fantasy-Related

Sites. From the Schenectady County Public Library, this megasite lists numerous useful resources, including newsgroups and electronic lists archives, topic and genre bibliographies, author and association sites, convention and fan Webs, magazines and newsletters, study guides, and research sources. While obviously very selective, the Web pages listed all appear to be active and based on the either usefulness of the information or on the reliability of the source. Access. http://www.scpl.org/sfsites html.

- Science Fiction and Fantasy Research Database. This site is the electronic incarnation of Hal W. Hall's "Science Fiction and Fantasy Research Index" (including all three volumes plus updates). It covers all aspects of science fiction, fantasy, horror, supernatural, and weird fiction, including criticism, commentary, reviews, and some fan material from more than 100 mainstream, literary, and science fiction sources, mainly in English. There are currently more than 50,000 items included, dating from 1878 to present. Access: http// library.tamu.edu/cushing/sffrd/.

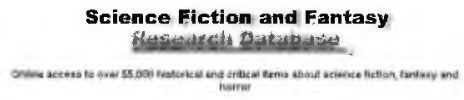

- Science Fiction Resource Guide. From SF-Lovers, this is one of the more useful and long-term resources on the Web. It contains links to archives and mailing lists, science fiction artists, authors, awards, bibliographies and bookstores, conventions and comics, fiction and movie resources, reviews and criticism, role-playing and other SF-related gaming, television, and program guides. It also provides one of the more complete list of links to fandom sites. Access: http://www.sflovers.org/ SFRG/.

- Ultimate Science Fiction Web Guide. This fan-based site offers a wide variety of links, including thematic topics, motion pictures, conventions, information on SF in various countries, and others. It is valuable for the unique material presented, but despite a high rating from Google, the site is not well organized or kept current. Access: http:// WWw. magicdragon.com/UltimateSF/SFIndex.html.

\section{THE UL TIMATE SCIENCE FICTION WEB GIJUE}

\section{Professional associations}

Professional associations affiliated with science fiction tend to provide valuable information from both an academic and professional perspective. Given the plethora of SFF sites on the Web and the lack of authority control, using an association Web site as a starting point for research or finding SFF resources is an ideal solution.

- Horror Writers Association. While this site is focused on horror fiction and has a restricted Members Only section, there is a lot of information available to the public at-large; author Web sites, award information (with a lot of focus on the Stoker Award), book lists, readings lists, writings tips, and a fairly detailed and lengthy listing of links to horror related sites are included. A gallery of horror 
art, both affiliated with textual creations and those standing alone, figures prominently alongside photos, conventions, and other events. Access: http://www.horror.org/

- The Heinlein Society. Author-specific sites can be of great benefit, especially when looking for lesser-known works or pseudonyns affiliated with a specific author, research collections, correspondence, experts, or affiliations. The Heinlein Society is a prime example of one of the many author sites on the Web, unique in that its emphasis as an educational charity. Access: http://www.heinleinsociety.org/ indexflash.html.

- International Association of the Fantastic in the Arts. This site focuses on member-exclusive information and has conference and journal information. While the content is fairly sparse, it does contain a listing of links "of interest to teachers and scholars of the fantastic" and bibliographic information on items appearing in the Journal of the Fantastic in the Arts. Access: http://ebbs.english.vt.edu/iafa/ iafa.home.html

- New England Science Fiction Association (NESFA). While admittedly regionally based, the NESFA site contains some useful information that is not just associationspecific in the form of reading lists, reviews, links to articles and fanzines, calendar of events, and links to other associations, clubs, and publishers. An affiliation with the NESFA Press also provides up-to-date catalogs, publishing news, forthcoming books, and writing advice. Access: http://www.nesfa.org/.

- Science Fiction and Fantasy Writers of America. This is another site with some information restricted to members only, but it does include a wealth of information available to anyone. The focus is admittedly to the benefit of authors, posting members' fiction and Web pages, book reviews and awards, and dates of readings and signings, in addition to topics relevant to writing as a profession, such as piracy, ergonomics, and writing as a business and as a craft. Access: http://www. sfwa.org/.

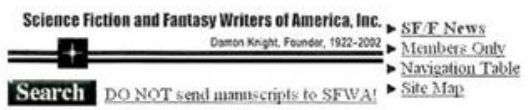

- Science Fiction Research Association (SFRA). The SFRA site may be brief in its con- tent, but it takes a more scholarly approach to science fiction, offering calls for papers, conference information, links to the SFRA Review and publishing guidelines, and news items of import. Access: http://www.sfra.org/

\section{Topical and genre listings}

Topical and genre listings are all over the Web, offering highly specific topical material (from both fan and scholarly perspectives). The following examples only hint at the breadth of the material available.

- Feminist Science Fiction, Fantasy, and Utopia. An extensive and fairly current site that has sections on "Bibliographies and Reviews," "Research, Criticism and Teaching," and other resources concerning the "Feminist SF Community." Some topics included are Amazon societies, feminist dystopias, sex war, feminist cyberpunk, and alternative HerStory. Access: http://www.feministsf.org/.

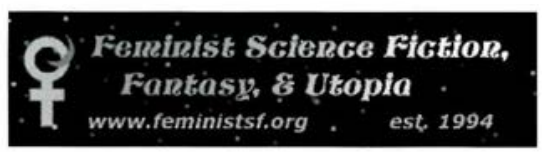

- Gary Westfahl's Biographical Encyclopedia of Science Fiction Film. Affiliated with Interzone and housed on the SF Site, this is an interesting online encyclopedia development. It is essentially a filmography, providing brief personal information, such as years of birth (and death), nationality and principal avocation (actor, director, producer, writer, special effects artist, composer, other), and complete lists of all films and television programs relevant to science fiction. Access: http://www.sfsite.com/interzone/ gary/intro.htm.

- Genre Evolution Project. This unique scholarly project tests the hypothesis that "cultural creations evolve in the same way as biological organisms." It indexes mainly science fiction short stories in 20th-century America by title, author, genre, and theme and summarizes selected results of their research. Access: http://www.umich.edu/ genreevo/.

- Mormon SF Bibliography. Though this site is nonacademic and remains fairly static, this bibliography contains works published by and about Latter-day Saint authors, including novels, short stories, poetry, and theses/dissertations, articles, and interviews. Access: http://home.earthlink.net/ marnyparkin/. 
- Prehistoric Fiction Bibliography. This is an annotated listing of 975 prehistoric novels and stories, organized by author's name, title, or publication date. Unlike other sites, it is not restricted to mainly English-language materials and does include foreign language annotations. Access: http://www.trussel.con/prehist/ prehist1.htm.

\section{PREHISTORIC FICTION}

Powistaric fictian

A literay geowe. juicipal daractes are mabers of a protustivic joriery.

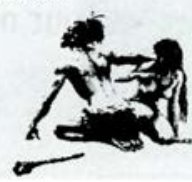

- STasis Your Guide to the Scholarly Literature of TREK. With more than 500 abstracts, summaries, and references to reli able, authoritative Star Trek information sources on entertainment, biographies, merchandise, trivia, fashion, food (Terran and Alien), gambling, and psychology, as well as news on television, films, and video games, this site could be titled "Everything you wanted to know about Star Trekbut were afraid to ask." Access: http://www.ircriise.com/stasis/.

- Time Travel Bibliography. Definitely a bare bones resource, this bibliography includes more than 3,200 items concerning time travel in science fiction. It is searchable by author, title, magazine, subject, locale, plot, method, and series. The best way to browse is to choose a field and search using "\%," Access: http:// www.timetravellit.com/index.php.

\section{Electronic journals and magazine directories}

- Del Rey Internet Newsletter. Oftentimes, publisher sites can be of specific help. One excellent example is the Del Rey Internet Newsletter with author interviews, annotations and sample chapters, book notes, book signings, and release scheclules. Access: http://www.randomhouse.com/delrey/ drindex/.

- Science Fiction and Fantasy Magazines on Yahoo In the constantly changing Web environment, this is the most comprehensive listing of magazines, journals, and zines in the gente. It includes links to illustrious titles such as Asimov's Science Fiction, Cinefex and Strange Horizons among many others. Access: http://dir yahoo.com/Arts/Humanities/Literature/Genres/Science_Fiction_and_Fantasy/ Magazines/.

- SF Crowsnest. Even though the field of electronic publishing is in a continual state of change, this site provides a fairly current and stable listing of e-journals and e-zines in science fiction and fantasy, and is searchable and browsable by format and type of information. Access: http://www computercrowsnest. com/directory/fdmags.shtml.

- Science Fiction Weekly. A product of the SciFi Channel, Science Fiction Weekly presents itself as the newspaper of the SFF genre It contains news on fiction, television, comics, games, and cinema in addition to polls, letters, and multimedia tidbits. Access: http:// www.scifi.com/sfw/.

- Tangent Online. This listing of magazines and newsletters of varying frequency includes anthologies and collections, news, and editorials, concentrating on short fiction in science fiction and fantasy. It includes reviews and tables of contents. Access: http://www tangentonline.com/.

\section{Miscellaneous sites of interest}

- The Best Science Fiction and Fantasy. This is an abbreviated listing of the major science fiction and fantasy award winners. Browsable by author, title, or award-winning year, the site provides bibliographic information (with links, admittedly infrequent, to re views and book store availability) and awards won, specifically the Campbell, Nebula, Hugo, and Locus awards. Access: http://woww bestsf.com.

- Definitions of Science Fiction. While the scope of this site is pretty narrow and the source is nonacademic, it provides an interesting variety of definitions for science fiction from masters of the genre, such as Isaac Asimov, Joseph Campbell, Lester del Rey, Hugo Gernsback, Frank Herbert, Sam Moskowitz, and many others. It includes provenance and citations where possible. Access: hup:// www.panix.com/ gokce/sf_defn.html.

- The Linköping Science Fiction and Fantasy Archive. This site has an archive of usenet postings of book and movie reviews, fan fiction and fan art, as well as clipart and graphical images. Access: http://sf.www.lysator.liu.se/sf_archive/ sf_main.html. 